\title{
Ganglioside-Enhanced Neurite Growth: Evidence for a Selective Induction of High-Molecular-Weight MAP-2
}

\author{
Adriana Ferreira,' Jorge Busciglio, ${ }^{1}$ Carlos Landa, ${ }^{2}$ and Alfredo Caceres' \\ IInstituto de Investigacion Medica Mercedes y Martin Ferreyra, 5000 Cordoba, and ${ }^{2}$ Departamento de Quimica Biologica, \\ Facultad Ciencias Quimicas (U.N.C), 5016 Cordoba, Argentina.
}

\begin{abstract}
Neuroblastoma cells maintained in serum-free medium exhibit a significant induction of MAP-1a and Tau proteins, but not MAP-2; the time course of these inductions is highly correlated with an increase in microtubule mass which parallels neurite growth. Bovine brain gangliosides (BBG) enhance the neurite outgrowth response of these cells. We report here that one effect of gangliosides is the selective and dramatic induction of MAP-2 expression. Our results also indicate a strong parallelism between this induction and the increase in microtubule mass which accompanies the appearance of more numerous, longer, and highly branched neurites. These observations suggest that MAP-2 induction in neuroblastoma cells may lead to a further differentiation of neurites equivalent to that observed in mature brain neurons. Finally, our results indicate that gangliosides per se are not neuritogenic factors but rather substances capable of enhancing cell-derived influences which affect the neurite outgrowth response of neuroblastoma cells and the type of MAP that they express.
\end{abstract}

Gangliosides are glycosphyngolipids which are integral components of neuronal membranes and seem to have a prominent role as regulators of neurite development and repair. Thus, several studies have demonstrated that the ganglioside composition of brain cells changes during development (Willinger and Schachner, 1980; Koulakoff et al., 1983; Matta et al., 1986; Maccioni et al., 1988; Gravotta et al., 1989) and after injury (Robb and Keynes, 1984), and that exogenously administered gangliosides are able to dramatically enhance neurite outgrowth in vitro (Byrne et al., 1983; Ferrari et al., 1983; Facci et al., 1984; Katoh-Semba et al., 1984; Skaper et al., 1985; Leon et al., 1988) and nerve regeneration in vivo (Gorio et al., 1980, 1983; Robb and Keynes, 1984; Sbasching-Agler et al., 1984). The mechanisms underlying these growth responses are therefore of considerable interest; unfortunately, little information exists regarding the elements of the neuron modified by gangliosides during neurite extension nor the way in which these modifications are brought about.

\footnotetext{
Received Apr. 19, 1989; revised July 11, 1989; accepted July 13, 1989.

We thank Dr. Federico Cumar and Laboratorios Beta (Argentina) for the gangliosides used in this study; Dr. W. Shayne for the generous gift of the neuronal tumor cells lines; and also Dr. L. Binder, A. Matus, and G. Piperno for the monoclonal antibodies. This work was supported by grants from CONICET, CONICOR, and Fundacion Perez Companc to A.C.

Correspondence should be addressed to Alfredo Caceres, Department of Neurology (CND), Brigham and Women's Hospital, Harvard Medical School, 75 Francis Street, Boston, MA 02115.
}

Copyright (C) 1990 Society for Neuroscience $0270-6474 / 90 / 010293-10 \$ 02.00 / 0$
Since microtubule formation is one of the key events during neurite elongation both during development (Barlett and Banker, 1984; Drubin et al., 1985; Caceres et al., 1986; Jacobs and Stevens, 1986) and repair (Hoffman and Lasek, 1980; Lasek, 1981; Busciglio et al., 1987), it may well be that gangliosides exert their action modifying and/or enhancing the expression of microtubule-associated proteins, MAPs (Matus, 1988), known to regulate tubulin polymerization and microtubule stability during nerve cell differentiation and process extension (Greene et al., 1983; Drubin et al., 1985, 1988; Black et al., 1986; Couchie et al., 1986; Brugg and Matus, 1988).

Therefore, in the present study we have used cultures of neuroblastoma cells to analyze the relationship between microtubule formation and neurite extension after ganglioside treatment. In addition, we have correlated both of these events with the time course of expression, levels, and distribution of MAPla, HMW-MAP2, and Tau proteins. We report here that exogenously supplied gangliosides selectively and dramatically enhance the expression of MAP-2, a protein normally present at very low levels in neuroblastoma cells. Our results also indicate a strong parallelism between this induction and the increase in microtubule mass which accompanies the enhanced neurite outgrowth response of ganglioside-treated cells.

\section{Materials and Methods}

Cell cultures. Neuroblastoma cells (N 115 or S 26 clones) were originally obtained from Dr. William Shayne (New York Health Center, Albany, NY). They were grown on RPMI medium supplemented with $5 \%$ horse serum; cells were cultured in a humidified $37^{\circ} \mathrm{C}$ incubator with $\mathrm{CO}_{2}$ atmosphere. Cells were plated onto poly-l-lysine-treated Aclar coverslips at densities ranging from 1000 to 20,000 cells $/ \mathrm{cm}$. After plating they were maintained in serum-free medium supplemented with the N2 mixture of Bottenstein and Sato (1979). When appropriate, dibutyryl cAMP (dbcAMP) was added at 1 or $10 \mathrm{mM}$. Experimental cultures were treated with a mixture of bovine brain gangliosides (BBG) at concentrations of 1,10 , or $100 \mu \mathrm{g} / \mathrm{ml}(18 \%$ GMl, $44 \%$ GDla, $15 \%$ GDlb, $20 \% \mathrm{GT}$; Laboratorios Beta, Argentina) or $1-10 \mu \mathrm{g} / \mathrm{ml}$ purified GM1 (a gift from Dr. Federico Cumar, Department of Biological Chemistry, National University of Cordoba, Argentina). For some experiments, culture medium was replaced with fresh one containing $10^{-6} \mathrm{M}$ colchicine; cells were then maintained in this medium for 3 or $6 \mathrm{hr}$.

Mean total neuritic length of individual neurons was quantified on camera lucida drawings of cell cultures stained with a monoclonal antibody $(\mathrm{mAb})$ that recognizes all $\beta$-tubulin isotypes, clone Tu9B (Caceres et al., 1986), using a semiautomatic image analyzer. The probability of branching, $P(\mathrm{br})$, and the mean number of neuritic segments were determined as described by Caceres and Steward (1983). Immunocytochemistry was performed as reported elsewhere (Caceres et al., 1986).

Microtubule protein level determination. Cytosolic or detergent-extracted cytoskeletal fractions were prepared as described by Drubin et al. (1985), and the levels of several microtubular proteins (tubulin, acetylated $\alpha$-tubulin, MAP-1a, MAP-2, and Tau) were determined by 
Table 1. Effect of gangliosides on the total neuritic length of neuroblastoma cells (S26 clone) maintained in serum-free medium

\begin{tabular}{lcclr} 
& \multicolumn{5}{l}{ Time after plating (d) } \\
\cline { 2 - 5 } Type of treatment & 1 & 3 & 5 & 7 \\
\hline- & $48 \pm 4^{b}$ & $132 \pm 9$ & $233 \pm 14$ & $475 \pm 31$ \\
dbcAMP $(1 \mathrm{~mm})$ & $62 \pm 8$ & $210 \pm 8$ & $320 \pm 16$ & $620 \pm 38$ \\
BBG $(10 \mu \mathrm{g} / \mathrm{ml})$ & $180 \pm 9$ & $550 \pm 35$ & $875 \pm 75$ & $1420 \pm 84$ \\
GMl & $168 \pm 11$ & $515 \pm 18$ & $880 \pm 35$ & $1250 \pm 75$ \\
\hline
\end{tabular}

A total of 25 cells was measured for each time point and experimental condition.

"Each value represents the mean \pm SEM. All values are expressed in $\mu \mathrm{m}$.

dot immunobinding (Caceres et al., 1988) with mAbs (Ferreira and Caceres, 1989; Ferreira et al., 1989). Standard curves were constructed and the amount of each of the proteins analyzed in unknown samples was determined by extrapolation of the linear regions of the unknown to the linear proteins of the standards.

For preparing cytosolic fractions, cultures were rinsed twice in warmed PBS and then scraped onto Laemmli reducing solution (Laemmli, 1970) and homogenized in a boiling water bath for $5 \mathrm{~min}$. The homogenate was centrifuged at 33,000 rpm; the supernatant was then removed and either used immediately or stored at $-80^{\circ} \mathrm{C}$. For preparing detergentextracted cytoskeletons, cultures were rinsed twice in microtubule stabilizing buffer (MTSB: $0.13 \mathrm{~m}$ Hepes, $\mathrm{pH} 6.9,2 \mathrm{~mm} \mathrm{MgCl}_{2}, 10 \mathrm{~mm}$ EGTA) and then extracted in the same buffer plus $0.2 \%$ Triton X-100 for $8 \mathrm{~min}$ (see also, Ferreira et al., 1989). After extraction, the coverslips were washed in MTSB and the detergent-extracted cytoskeletons scraped onto Laemmli reducing solution as described; this material was then centrifuged and the DNA-containing pellet removed. All buffers used for protein extractions contain $10 \mu \mathrm{g} / \mathrm{ml}$ aprotinin, $10 \mu \mathrm{g} / \mathrm{ml}$ pepstatin, and $1 \mathrm{~mm}$ phenylmethylsulfonylfluoride.

\section{Results}

Neuroblastoma cells cultured in the presence of serum have a round morphology. When these cells are deprived of serum, they acquire morphological characteristics of neurons, extending several thick neurites (3-5 processes/cell) with few branches (Fig. 1; Tables 1, 2). The addition of dbcAMP to the N2 mixture of Bottenstein and Sato (1979) results in a dose-dependent increase in neurite length, even though the morphology and branching pattern of the neurites do not change significantly (Tables 1, 2).

On the contrary, the addition of a mixture of BBG to the culture medium results in a dramatic increase in neurite length, a phenomenon which is highly correlated with an increase in the number of neurite branches per cell; this effect, which becomes evident $1 \mathrm{~d}$ after administration of gangliosides, is pre- ceded by the appearance of numerous, thin, spine-like projections (Fig. 1; Tables 1, 2). After $5 \mathrm{~d}$ in vitro (5 DIV), both the length of the primary neuritic trunks and of the fine ramifications have also increased significantly. An enhanced neurite outgrowth response is also observed after addition of GM1, but not of asialo-GM1, to the culture medium (Table 1).

In control cells, polymeric tubulin increases significantly and in parallel with neurite length (Table 3); acetylated or colchicineresistant microtubules begin to increase after the cells have developed for 3 DIV; after that time, both microtubule mass and stable microtubules increase in parallel (Table 3). A significant induction in MAP-la is also observed during the in vitro development of neuroblastoma cells; the time course of this induction accompanies the increase in polymeric tubulin and neurite length. Tau protein levels also increase but with a time course similar to that of the induction of stable microtubules; besides, Tau binds preferentially to colchicine-resistant cytoskeletons at all stages of development, as opposed to MAP-1a, which is initially associated with colchicine-labile microtubules (Table 3). A third well-known cofactor, MAP-2, is only slightly induced during the in vitro development of neuroblastoma cells (Table 3 ). The above described pattern is also observed after the addition of dbcAMP (Fig. 2) or a high dose of insulin (50 $\mu \mathrm{g} / \mathrm{ml}$ ) to the serum-free medium (data not shown).

Ganglioside-treated cells exhibit a similar induction profile in terms of MAP-1a and Tau proteins; however, the addition of these substances to the culture medium results in a dramatic induction of MAP-2 (Fig. 2, Table 3), a phenomenon which is accompanied by an increase in microtubule mass which parallels the cnhanced ncuritc outgrowth responsc of thesc cells (Fig. 2). Immunocytochemical analysis of ganglioside-treated cells with mAbs that recognize high-molecular-weight MAP-2 (clones AP

Table 2. Effect of gangliosides on the number of neurite segments and the probability of branching, $P(b r)$, of neuroblastoma cells (S26 clone) maintained in culture for $5 \mathrm{~d}$ in serum-free medium

\begin{tabular}{llllll} 
& \multicolumn{5}{l}{ Order of neurite segments } \\
\cline { 2 - 6 } Treatment & 1st & 2nd & 3rd & 4th & 5th \\
\hline & $3.4 \pm 0.5^{a}$ & $2.8 \pm 0.7$ & $1.2 \pm 0.4$ & $0.5 \pm 0.3$ & $0.5 \pm 0.4$ \\
- & $(0.41)^{b}$ & $(0.18)$ & $(0.16)$ & $(0.16)$ & $(-)$ \\
dbcAMP $(1 \mathrm{~mm})$ & $4.6 \pm 0.4$ & $3.4 \pm 0.8$ & $2.4 \pm 0.8$ & $1.5 \pm 0.5$ & $0.7 \pm 0.3$ \\
& $(0.45)$ & $(0.22)$ & $(0.20)$ & $(0.18)$ & $(-)$ \\
BBG $(10 \mu \mathrm{g} / \mathrm{ml})$ & $8.0 \pm 0.5$ & $11.4 \pm 1$ & $12.5 \pm 0.8$ & $14.4 \pm 0.6$ & $22.1 \pm 0.7$ \\
& $(0.64)$ & $(0.54)$ & $(0.67)$ & $(0.73)$ & $(-)$
\end{tabular}

"Each value represents the mean \pm SEM.

${ }^{\circ}$ The number in parentheses represents $P(b r)$ for first-, second-, third-, and fourth-order neurites. These values were determined as described by Caceres and Steward (1983). 

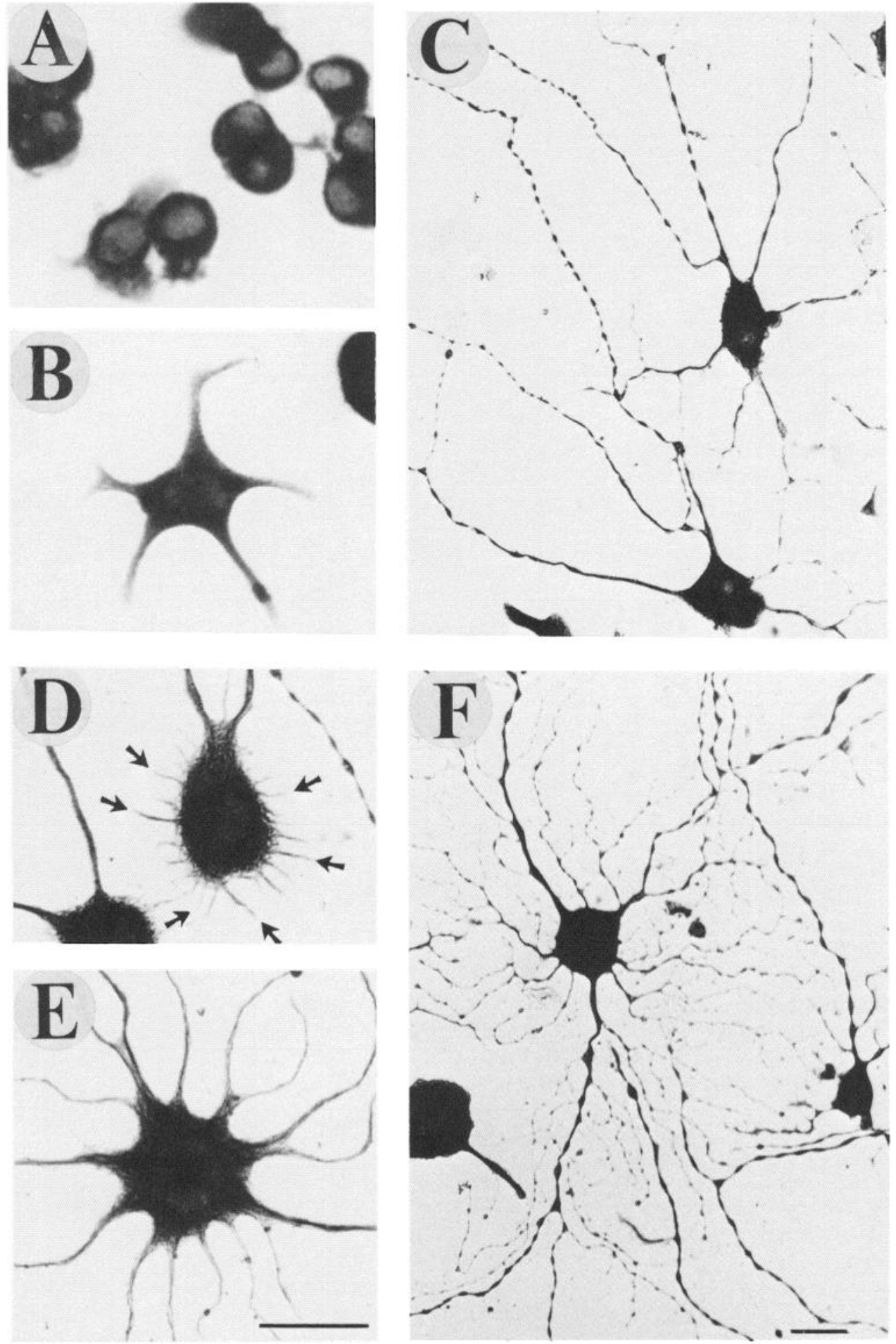

Figure 1. Bright-field micrographs showing neuroblastoma cells cultured in serum-supplemented medium $(A)$, in serum-free medium for $1 \mathrm{~d}(B)$ or $5 \mathrm{~d}$ $(C)$ and $12 \mathrm{hr}(D), 1 \mathrm{~d}(E)$, and $5 \mathrm{~d}(F)$ after the addition of BBG $(10 \mu \mathrm{g} / \mathrm{ml})$ to the culture medium. Note the appearance of numerous spinelike projections shortly after ganglioside treatment ( $\mathrm{ar}$ rows) and the dramatic increase in neurite number and length with subsequent development in vitro. The cells shown in $D$ are stained with a $\mathrm{mAb}$ against MAP-2, while the others are stained with a $\mathrm{mAb}$ against $\beta$-tubulin. Scale bars, $50 \mu \mathrm{m}$.
9 or AP 14) reveals strong immunoreactivity for this protein in the thick neuritic trunks and in the numerous and thin branches that they extend (Fig. 3); immunoreactivity is also detected in growth cones and spinelike projections (see Fig. 3. 1D, 5).

This pattern is not attributable solely to unbound MAP-2 since immunoreactivity is retained in the neurites following extractions with Triton X-100 under conditions that remove unpolymerized cytoskeletal subunits but preserve microtubules (see Table 3). Our results also show that MAP-2 is initially associated with colchicine-labile cytoskeletons and that the thin neurite branches are lost after $1 \mathrm{hr}$ exposure to this drug; after 3 DIV, both of them become progressively drug-resistant. An increase in the amount of MAP-1a and Tau bound to the cytoskeleton, as well as in the levels of total Tau, tubulin, and colchicine-resistant microtubules is also observed in long-term gangliosides-treated cultures (Table 3 ).

Having shown that neurite outgrowth, microtubule assembly, and the expression of MAP-2 are greatly enhanced after gan- 
Table 3. Variations in tubulin, MAP-1a, MAP-2, and TAU protein levels ${ }^{a}$ during the in vitro development of neuroblastoma cells in the presence or absence of bovine gangliosides

\begin{tabular}{|c|c|c|c|c|}
\hline \multirow[b]{2}{*}{ Substance } & \multicolumn{4}{|c|}{ Time after plating (d) } \\
\hline & 1 & 3 & 5 & 7 \\
\hline \multicolumn{5}{|l|}{ Tubulin } \\
\hline \multicolumn{5}{|l|}{ Control cells } \\
\hline Cytosolic fraction & $23.0 \pm 2.0$ & $32.0 \pm 4.0$ & $36.0 \pm 2.0$ & $46.0 \pm 2.0$ \\
\hline Cytoskeletal fraction & $5.0 \pm 0.5$ & $9.0 \pm 2.0$ & $14.0 \pm 2.0$ & $19.0 \pm 2.0$ \\
\hline Cytoskeletal fraction C.R. & $0.4 \pm 0.1$ & $1.5 \pm 0.2$ & $5.0 \pm 0.5$ & $9.0 \pm 2.0$ \\
\hline \multicolumn{5}{|l|}{ BBG-treated cells } \\
\hline Cytosolic fraction & $24.0 \pm 2.0$ & $33.0 \pm 4.0$ & $40.0 \pm 2.0$ & $54.0 \pm 4.0$ \\
\hline Cytoskeletal fraction & $8.0 \pm 1.0$ & $16.0 \pm 2.0$ & $22.0 \pm 1.0$ & $29.0 \pm 4.0$ \\
\hline Cytoskeletal fraction C.R. & $0.6 \pm 0.1$ & $2.0 \pm 0.2$ & $8.0 \pm 0.4$ & $15.0 \pm 1.5$ \\
\hline \multicolumn{5}{|l|}{ MAP-1a } \\
\hline \multicolumn{5}{|l|}{ Control cells } \\
\hline Cytosolic fraction & $0.5 \pm 0.1$ & $0.9 \pm 0.2$ & $1.8 \pm 0.4$ & $2.6 \pm 0.2$ \\
\hline Cytoskcletal fraction & $0.2 \pm 0.1$ & $0.5 \pm 0.1$ & $1.5 \pm 0.2$ & $2.0 \pm 0.2$ \\
\hline Cytoskeletal fraction C.R. & $-\quad-$ & $0.05 \pm 0.01$ & $0.5 \pm 0.1$ & $1.1 \pm 0.2$ \\
\hline \multicolumn{5}{|l|}{ BBG-treated cells } \\
\hline Cytosolic fraction & $0.5 \pm 0.1$ & $1.1 \pm 0.2$ & $1.9 \pm 0.4$ & $2.6 \pm 0.2$ \\
\hline Cytoskeletal fraction & $0.3 \pm 0.1$ & $0.4 \pm 0.1$ & $1.7 \pm 0.2$ & $2.5 \pm 0.2$ \\
\hline Cytoskeletal fraction C.R. & $-\quad-$ & $0.05 \pm 0.01$ & $0.5 \pm 0.1$ & $1.3 \pm 0.2$ \\
\hline \multicolumn{5}{|l|}{ MAP-2 } \\
\hline \multicolumn{5}{|l|}{ Control cells } \\
\hline Cytosolic fraction & $0.09 \pm 0.01$ & $0.12 \pm 0.01$ & $0.17 \pm 0.01$ & $0.32 \pm 0.01$ \\
\hline Cytoskeletal fraction & $-\quad-$ & $-\quad-$ & $-\quad-$ & $0.14+0.01$ \\
\hline Cytoskeletal fraction C.R. & - & - & - & $-\quad-$ \\
\hline \multicolumn{5}{|l|}{ BBG-treated cells } \\
\hline Cytosolic fraction & $0.9 \pm 0.2$ & $2.6 \pm 0.3$ & $4.8 \pm 0.5$ & $5.4 \pm 0.4$ \\
\hline Cytoskeletal fraction & $0.7 \pm 0.2$ & $2.0 \pm 0.4$ & $4.2 \pm 0.4$ & $5.1 \pm 0.4$ \\
\hline Cytoskeletal fraction C.R. & $0.05 \pm 0.01$ & $0.3 \pm 0.04$ & $0.8 \pm 0.1$ & $1.8 \pm 0.2$ \\
\hline \multicolumn{5}{|l|}{ Tau } \\
\hline \multicolumn{5}{|l|}{ Control cells } \\
\hline Cytosolic fraction & $0.07 \pm 0.01$ & $0.15 \pm 0.01$ & $0.30 \pm 0.08$ & $0.65 \pm 0.04$ \\
\hline Cytoskeletal fraction & $0.03 \pm 0.01$ & $0.10 \pm 0.01$ & $0.20 \pm 0.05$ & $0.60 \pm 0.04$ \\
\hline Cytoskeletal fraction C.R. & $0.02 \pm 0.01$ & $0.12 \pm 0.02$ & $0.20 \pm 0.06$ & $0.60 \pm 0.03$ \\
\hline \multicolumn{5}{|l|}{ BBG-treated cells } \\
\hline Cytosolic fraction & $0.07 \pm 0.01$ & $0.25 \pm 0.02$ & $0.45 \pm 0.05$ & $0.85 \pm 0.05$ \\
\hline Cytoskeletal fraction & $0.03 \pm 0.01$ & $0.20 \pm 0.02$ & $0.40 \pm 0.06$ & $0.75 \pm 0.05$ \\
\hline Cytoskeletal fraction C.R. & $0.02 \pm 0.01$ & $0.18 \pm 0.02$ & $0.40 \pm 0.04$ & $0.75 \pm 0.05$ \\
\hline
\end{tabular}

“Tubulin, MAP-1a, MAP-2 and Tau protein levels were determined by quantitative dot immunobinding using ${ }^{125}$ Protein $A$ as described in Materials and Methods.

${ }^{n}$ Each value represents the mean \pm SEM from measurements of 5 neuroblastoma cultures grown on $16 \mathrm{~mm}$ Aclar coverslips. Values are expressed in micrograms per milligram of total cellular protein.

C.R., colchicine-resistant.

glioside treatment, we sought to determine if these effects were related with cell density and/or cell-cell interactions. For this purpose we examined the growth of $\mathrm{S} 26$ neuroblastoma cells in low-density cell cultures maintained with the N2 mixture of Bottenstein and Sato (1979) supplemented with either dbcAMP and/or BBG. The addition of dbcAMP to isolated neuroblastoma cells results in a significant increase in MAP-1a and Tau immunoreactivity, but not MAP-2, a phenomenon which is correlated with the extension of several long unbranched neurites; under this condition, addition of BBG or GM1 does not change the neurite outgrowth response or the type of MAP that these cells express. A similar phenomenon is observed in neuroblastoma cells which grow as aggregates (5-10 cells) in lowdensity cell cultures.
However, if medium collected from high-density cell cultures ("conditioned medium") is supplemented with gangliosides and added to isolated neuroblastoma cells, significant increases in neurite length and MAP-2 immunoreactivity are detected (Fig. 4). These observations suggest the presence in the "conditioned medium" of substance capable of inducing the expression of MAP-2 whose activity is greatly enhanced after the addition of gangliosides. In order to further test this possibility, 2 other types of experiments were performed. The first involved determining the effect of "conditioned medium" obtained from cultures of different ages with and without BBG supplementation on the magnitude and time course of MAP-2 induction. Table 4 shows that MAP- 2 protein levels varies as a function of the age of the culture from which the "conditioned medium" is 

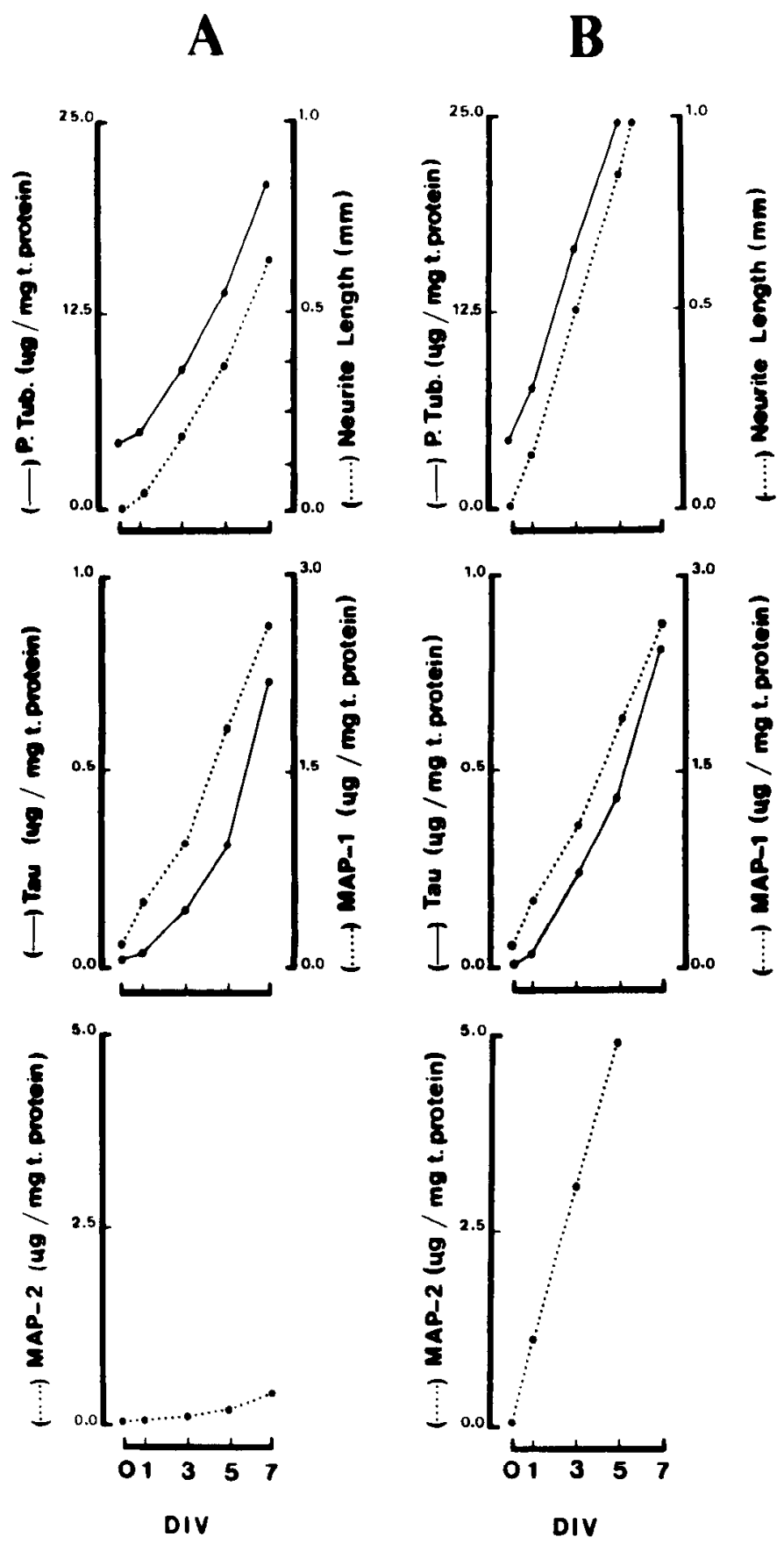

Figure 2. Quantitative evaluation of the changes in neurite length, microtubule mass (polymeric tubulin), MAP-1a, MAP-2, and Tau protein levels in neuroblastoma cells maintained in serum-free medium supplemented with either $1 \mathrm{~mm} \operatorname{dbcAMP}(A)$ or $10 \mu \mathrm{g} / \mathrm{ml} \mathrm{BBG}(B)$. Microtubule protein levels determined by dot immunobinding assay are expressed in micrograms per milligram of total cellular protein. DIV, days in vitro.

obtained; gangliosides are also more effective in stimulating this response in cells maintained with "conditioned medium" obtained from old cultures. The second type of experiment involved analyzing these effects of gangliosides on high-density cell cultures of different ages; the results obtained indicate that BBG or GM1 are more effective at inducing MAP-2 and increasing neurite length if they are added to cells which have already extended neurites (5 DIV cultures) as opposed to youn-
Table 4. MAP-2 induction in neuroblastoma cells maintained in vitro for $1 \mathrm{~d}$ with "conditioned medium" collected from cultures of different ages with or without bovine brain gangliosides (BBG) supplementation

\begin{tabular}{lll}
$\begin{array}{l}\text { Source of conditioned } \\
\text { medium }^{a}\end{array}$ & $\begin{array}{l}\text { BBG treatment } \\
(10 \mu \mathrm{g} / \mathrm{ml})\end{array}$ & $\begin{array}{l}\text { MAP-2 protein } \\
\text { levels }^{h}\end{array}$ \\
\hline 3-d-old cultures & - & $0.16 \pm 0.02$ \\
3-d-old cultures & + & $1.40 \pm 0.15$ \\
7-d-old cultures & - & $0.26 \pm 0.04$ \\
7-d-old cultures & + & $2.2 \pm 0.20$
\end{tabular}

" "Conditioned medium" was collected from high-density neuroblastoma cell cultures.

"MAP-2 protein levels were determined by dot immunobinding as described in Materials and Methods.

ger ones (1 DIV cultures). This phenomenon is accompanied by the appearance of numerous filopodia and growth cones at the tip and surface of primary and secondary neuritic trunks (Fig. 5).

\section{Discussion}

Neurite growth and MAP-2 induction in ganglioside-treated neuroblastoma cells

The present results support and extend previous observations indicating that the cytoskeleton changes significantly during ganglioside-enhanced neurite growth (Spero and Roisen, 1984; Ryback et al., 1983). In addition, they provide evidence strongly supporting the idea that MAP-2 is a key regulator of microtubule assembly during nerve process extension (Ferreira et al., 1989).

The neuritogenic response of neuroblastoma cells to exogenously supplied gangliosides has 2 phases. The first involves the outgrowth of numerous and thin neurites, a stage preceded by the appearance of spinelike projections resembling filopodia. In the second phase, the neurites elongate and stabilize. All these events led to a significant modification of cell shape. There are several common features between this neuritogenic response and the one of brain neurons which develop in culture. Thus, in hippocampal pyramidal cells or cerebellar macroneurons maintained in vitro, we can also distinguish 2 basic stages of neurite development. Initially, the cells extend several minor undifferentiated processes, and at a later stage these neurites elongate, branch, and stabilize; the initial stage of neurite development is preceded by the appearance of lamellipodia (Dotti et al., 1988; Ferreira and Caceres, 1989; Ferreira et al., 1989).

Each of these phases is characterized by the expression of a particular type of MAP; initially, the neurons express MAP-2 and later, Tau proteins. The induction of MAP-2 is associated with a significant increase in microtubule mass and neurite outgrowth, and the one of Tau with microtubule stabilization and further neurite elongation (Ferreira et al., 1989). If Tau is expressed earlier than MAP-2, as in cerebellar macroneurons which grow as microexplants, the cells stabilize their microtubules but do not extend neurites; it is only after MAP-2 induction that neurite growth begins. In ganglioside-treated neuroblastoma cells, the initial response involves the extension of numerous neurites and the induction of MAP-2; these neurites contain colchicinelabile microtubules and MAP-2 associated with them; at a later stage, the neurites elongate and their microtubules become colchicine-resistant. This phenomenon is accompanied by an increase in Tau protein levels and in the amount of Tau associated with the cytoskeleton. Thus, it secms that a sequence involving 

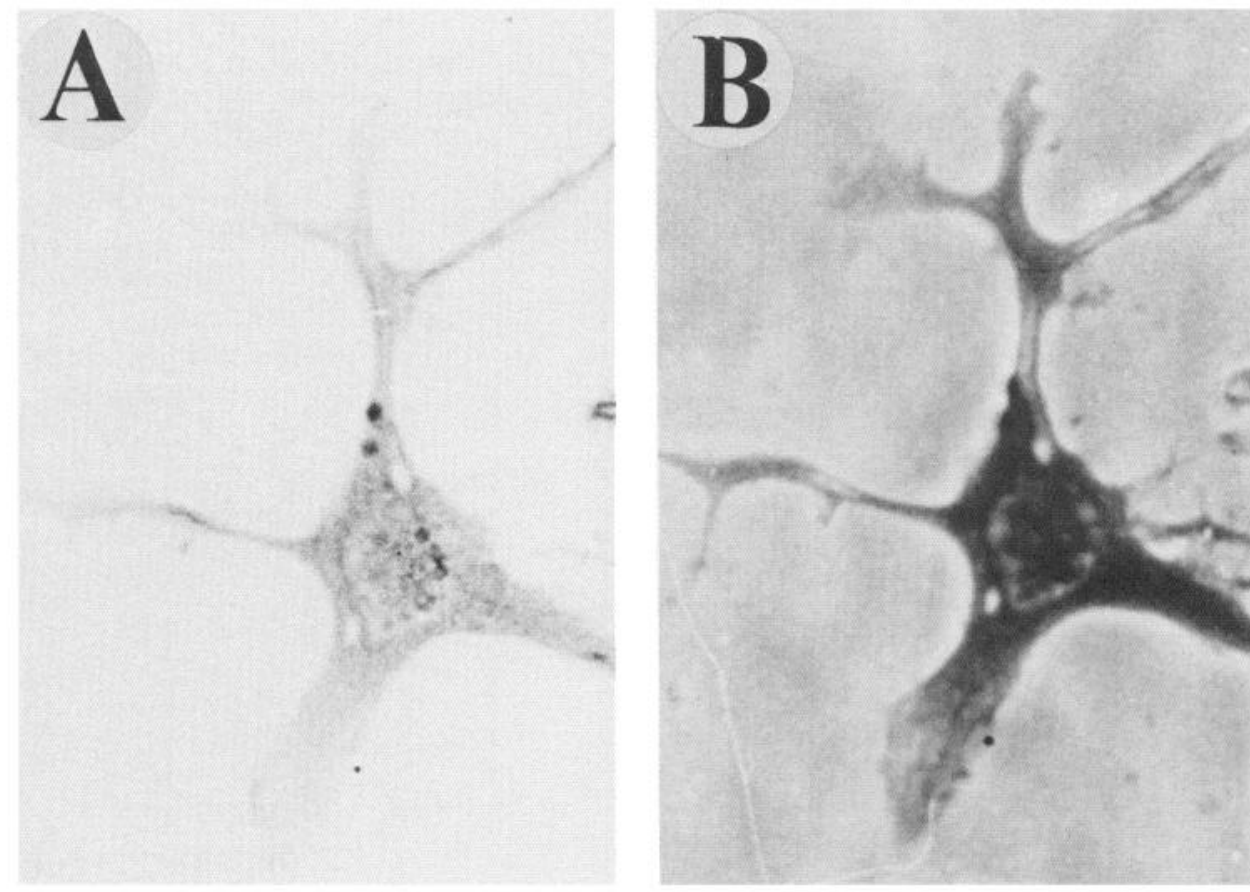

Figure 3. Expression of MAP-2 in neuroblastoma cells as revealed by immunocytochemistry with the $\mathrm{mAb}$ AP-14. A, Bright-field micrograph illustrating the absence of MAP-2 immunoreactivity in $\mathrm{S} 26$ cells maintained in serum free-medium. $B$, Corresponding phase-contrast micrograph. $C$, Bright-field micrograph showing strong MAP-2 immunoreactivity in S 26 cells maintained in serum-free medium supplemented with $10 \mu \mathrm{g} / \mathrm{ml} \mathrm{BBG;} \mathrm{note} \mathrm{the}$ intense staining of the cell body and of the neuritic truncks. Scale bar, $50 \mu \mathrm{m}$.

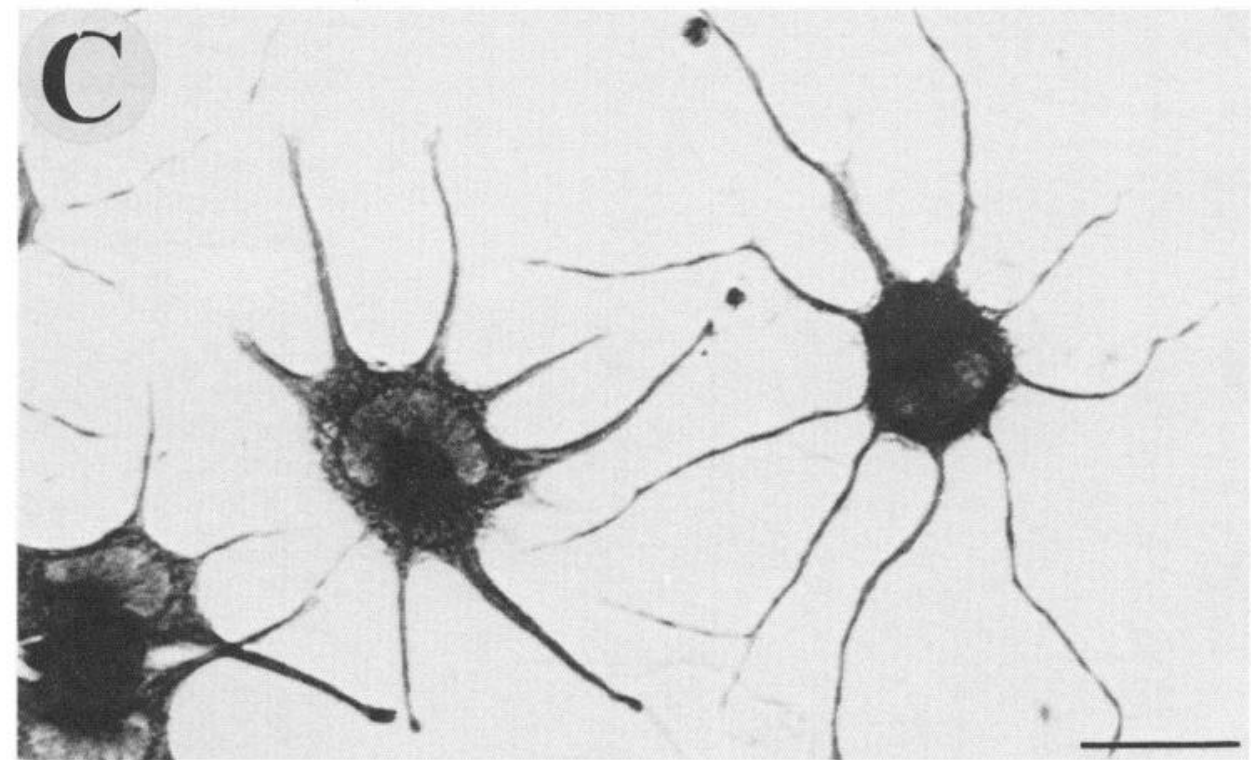

the expression of a microtubule polymerization-promoting factor followed by the one of a stablizing agent is required for initiating and maintaining neurite growth.

In neuronal tumor cells lines, which normally do not express MAP-2, other factors like MAP-1a (Greene et al., 1983; Drubin et al, 1985; this study), MAP-3, or MAP-5 (Brugg and Matus, 1988) may act as promoters of microtubule assembly, although they may not be as effective as MAP-2. Thus, in the absence of MAP-2, neuroblastoma cells only extend unbranched neurites, which are clearly different from those displayed by mature brain neurons, both in situ and in vitro, or by ganglioside-treated neuroblastoma cells; it seems as they were arrested at an earlier stage of differentiation. Interestingly, a similar profile of MAPs seems to be expressed by neuronal tumor cell lines and im- mature neurons, both types of nerve cells express high levels of MAP-3 and MAP-5 which are characteristic of developing neurons in the juvenile brain (Brugg and Matus, 1988).

MAP-2 induction, as in ganglioside-treated neuroblastoma cells, may led to a further differentiation of neurites equivalent to that observed in mature neurons. A causal relationship between these 2 events is supported by several observations. First, MAP-2 is a strong promoter of tubulin polymerization in vitro (Matus, 1988). Second, during neuronal development both in situ and in vitro, its expression is highly correlated with the morphological development of neurites and the appearance of microtubules (Caceres et al., 1986; Matus et al., 1986; Ferreira et al., 1987, 1989; Matus, 1988). Third, studies using primary cultures of brain neurons have shown that during nerve process 


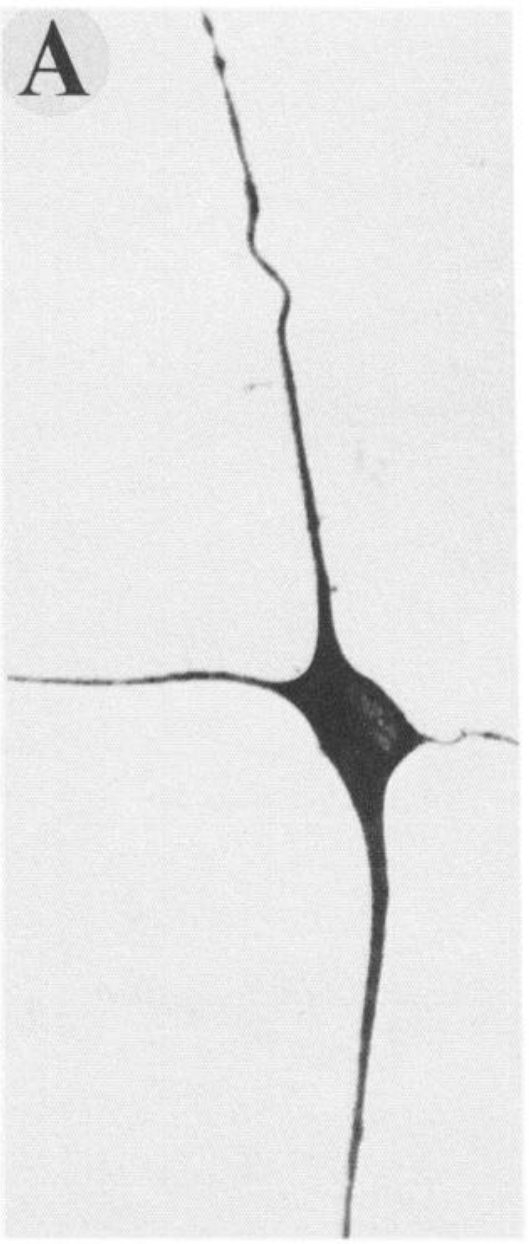

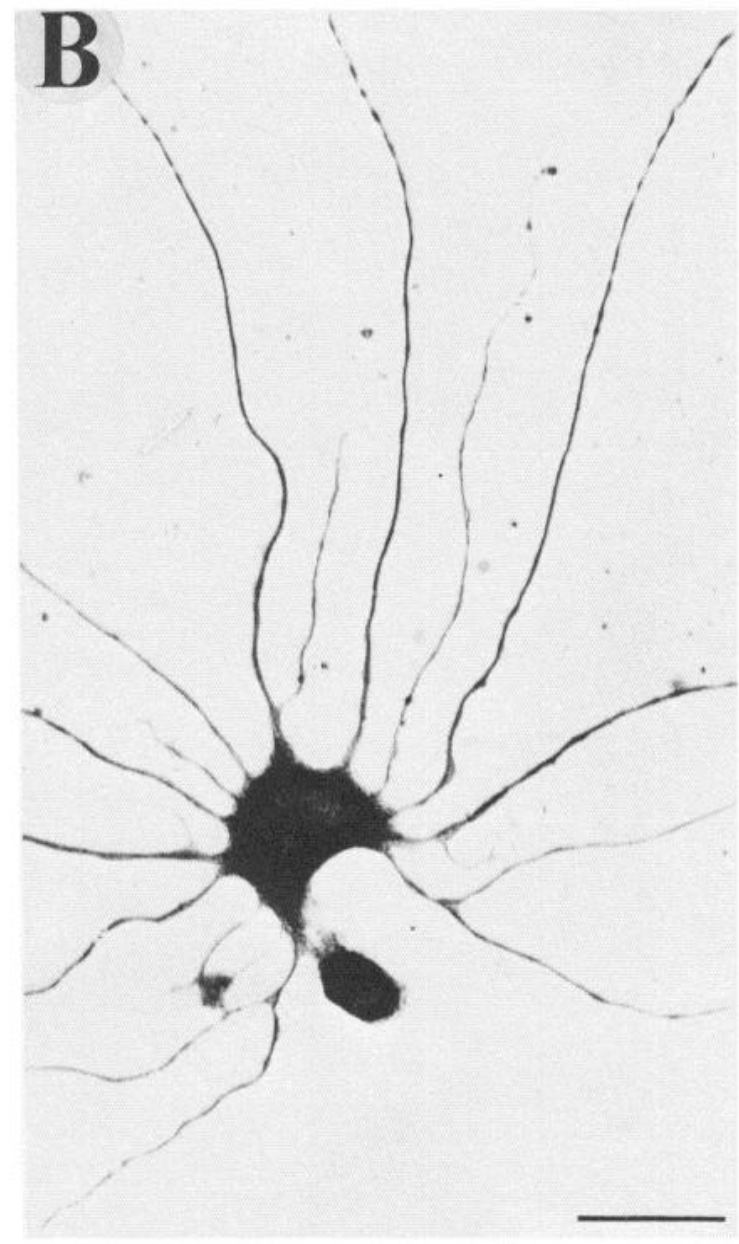

Figure 4. A, Bright-field micrograph showing a single isolated $\mathrm{S} 26$ cell maintained in serum-free medium plus gangliosides. $B$, An equivalent cell to that shown in $A$ but maintained with "conditioned medium" plus gangliosides; note the increase in the number of neurite branches and in total neurite length. The cell showed in $A$ was stained with a mAb against Tau, while the one in $B$ was stained with a mAb against MAP2. Scale bar, $50 \mu \mathrm{m}$. extension the stoichiometry of MAP-2 to tubulin is well within effective ranges for promoting microtubule assembly (Ferreira et al., 1989); a high ratio of MAP-2 to tubulin is also observed in ganglioside-treated neuroblastoma cells. Finally, variations in the magnitude and time course of MAP-2 induction, rather than of other MAPs, are highly correlated with dramatic increases in microtubule mass, in the number of neurites, and in neurite length, as in the case of "primed" cerebellar macroneurons (Ferreira et al., 1989) and neuronal tumor cell lines treated with retinoic acid (Fisher et al., 1986) or gangliosides (this study).

However, factors other than MAP-2 may also participate in determining the highly branched neuritic pattern of gangliosidetreated neuroblastoma cells. In this regard, it is noteworthy that ganglioside treatment of Neuro-2a cells produces significant changes in the organization and activity of the microfilament system, which are correlated with the appearance of spine-like projections along the neurites (Spero and Roisen, 1984); we observed a similar phenomenon in S 26 neuroblastoma cells not only when BBG are added to the culture medium at the beginning of neurite growth but also in cells which have already extended neurites. Interestingly, if Neuro-2a cells are grown under microfilament-limiting conditions, extension of the neurites still occurs, but the ability to acquire a branched pattern is lost; however, neurites with very long linear or slightly curved trajectories are observed. As proposed by Spero and Roisen (1984), the ability of neurites to form under this condiiton may reflect an accentuation or amplification of microtubule expres- sion induced by gangliosides; they compare this response as if the cells were treated with taxol. Our results would predict that this increase in microtubule mass and neurite length reflects the enhanced induction of MAP-2. On the other hand, if ganglioside-treated Neuro-2a cells are grown under microtubule limiting conditions, they extend spine-like projections all around the cell body which do not elongate even though they are potentially able to exhibit motile activity. It is tempting to speculate that in the presence of a promoter of tubulin polymerization like MAP-2, this motile activity may be inhibited, leading to directional growth and hence to the extension of a neurite branch (see also Mitchison and Kirschner, 1988). The fact that MAP-2 has been detected in the growth cones and filopodia of developing neurons (Caceres et al., 1986; this study) gives support to this idea.

The transition of lamellipodia to minor undifferentiated neurites which is observed in culture brain neurons may be explained by a similar mechanism, i.e., the expression of a microtubule-polymerization-promoting factor, the formation of microtubules, and the subsequent inhibition of actin-based protrusive activity; in the absence of microtubule-stabilizing factors, these minor neurites will not exhibit net growth. In fact, this has been observed in hippocampal pyramidal cells in culture (Dotti et al., 1988). At a further step, the expression of microtubule-stabilizing factors will led to elongation of the minor processes. The sequential appearance of these factors has already been described in cerebellar macroneurons and microneurons 
Figure 5. A, Phase-contrast micrograph showing a neuroblastoma cell maintained in serum-free medium after development in culture for $5 \mathrm{~d}$; BBG $(10 \mu \mathrm{g} / \mathrm{ml})$ were added to the culture medium on day 4 . Note the numerous neurite branches, spinelike projections, and growth cones that the cell displays. $B$, Corresponding bright-field micrograph of the cell shown in $A$ as revealed by immunocytochemistry with a mAb against MAP-2; note the labeling of the cell body, neurite trunks, and growth cones (arrows). Scale bar, $50 \mu \mathrm{m}$.
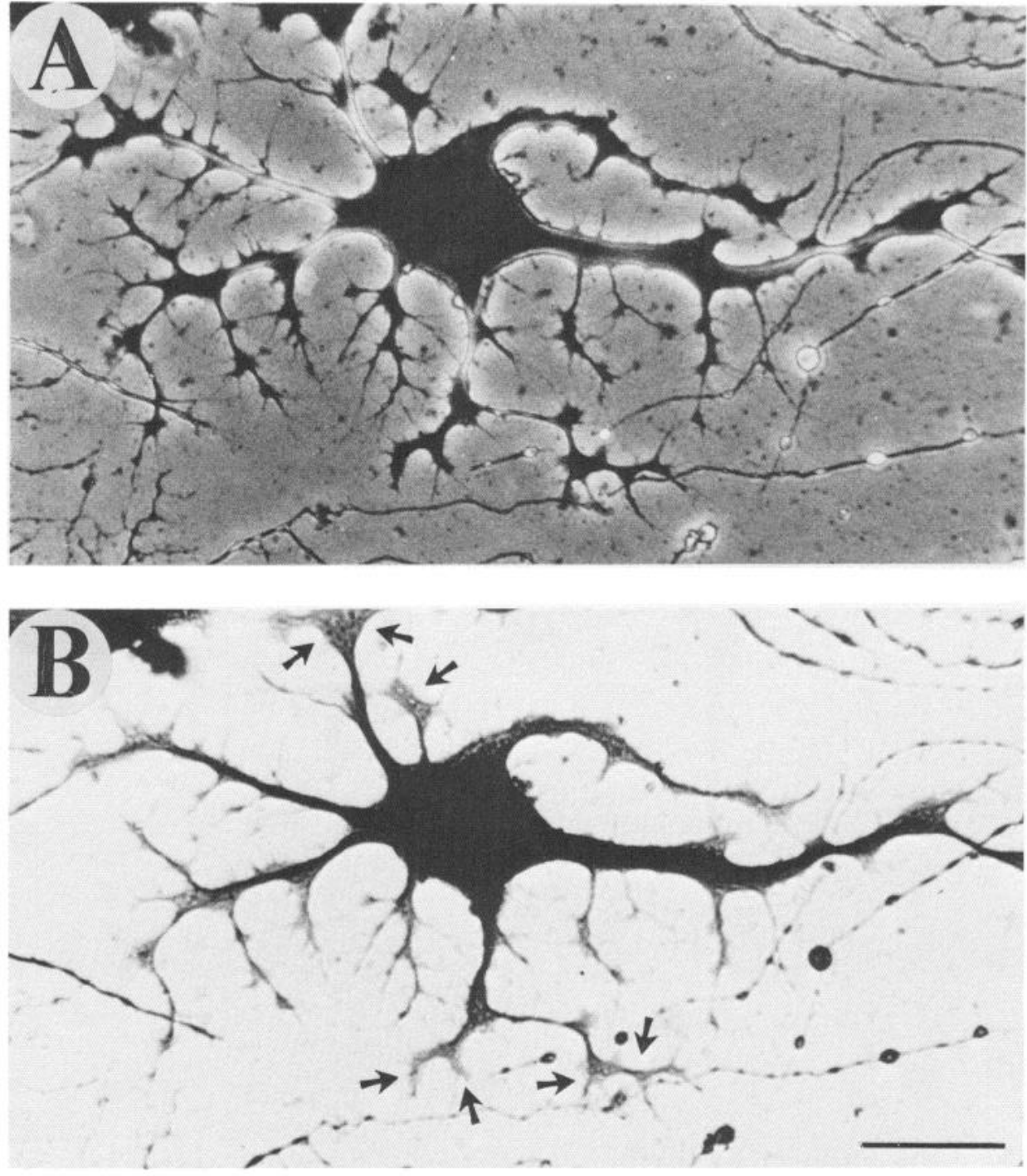

in culture (Cambray-Deakin et al., 1987; Ferreira and Caceres, 1989; Ferreira et al., 1989).

\section{Relationship between the ganglioside effect and neuritogenic influences}

Our observations suggest that gangliosides per se are not neuritogenic factors; rather, they are substances capable of greatly enhancing cell-derived influences which affect the neurite outgrowth response of nerve cells. These observations are fully in agreement with previous studies in different neuronal cell systems showing that gangliosides act to modulate the efficacy of trophic agents (Ferrari et al., 1983; Katoh-Semba et al., 1984; Doherty et al., 1985; Matta et al., 1986; Leon et al., 1988).

Ganglioside are ineffective in promoting neurite growth and inducing MAP-2 in low-density cell cultures but are effective at high density. This effect seems to be related to the presence in the culture medium of diffusable "neuritogenic" substances whose activity is potentiated after the addition of gangliosides. The induction of MAP-2 and the increase in neurite length observed in isolated cells maintained with "conditioned medium" plus gangliosides fully support this idea. This is also in accordance with the observations of Spoerri et al. (1988) show- ing an inhibition of conditioned media-mediated neurite outgrowth of sensory ganglia by mAbs to GM1.

In serum-deprived neuroblastoma cells, MAP-2 increases more than 3-fold after the cells have developed in vitro for $7 \mathrm{~d}$, although its ratio with respect to tubulin remains at a substoichiometric value. This induction may be related to a progressive accumulation in the culture medium of neuritogenic substances capable of regulating its expression; in the absence of factors like gangliosides, they may only exert a stimulatory effect on MAP-2 after they have accumulated considerably. An obvious prediction of this hypothesis would be that gangliosides have a more significant effect in older cells than in younger ones; the dramatic and very fast neurite outgrowth response and MAP-2 induction observed in neuroblastoma cells when gangliosides are added after $5 \mathrm{~d}$ in culture is in agreement with this proposal. Additional support for this idea comes from our observations showing that gangliosides are more effective in exerting these effects in cells maintained with "conditioned" medium from oider cultures than from younger ones.

The possible existence of diffusable neuritogenic substances capable of regulating the expression of MAP- 2 is not surprising. A dramatic induction of MAP-2 is observed in cerebellar macro- 
neurons maintained with "conditioned medium" obtained from suspension cultures (Ferreira et al., 1989). Interestingly, the profile of MAP-1a and Tau induction does not change significantly under this condition. Thus, a common feature of the cerebellar "conditioned medium" and of the one of neuroblastoma cell cultures is that they contain substances which are capable of inducing MAP-2, but not MAP-1a or Tau. It will now be of considerable interest to determine the nature of these factors, as well as the mechanisms by which gangliosides potentiate their action. In this regard, it is noteworthy that exogenous gangliosides are incorporated into membranes and can affect several of their properties (Spiegel et al., 1985; Tettamanti et al., 1985), and thus may increase the binding capacity of neuritogenic substances to their receptors (Hollmann and Seifert, 1986) or the receptor-mediated signal transduction (Bremer et al., 1984, 1986).

\section{References}

Barlett, W. P., and G. Banker (1984) An electron microscopic study of the development of axons and dendrites by hippocampal neurons in culture: Cells which develop without intercellular contacts. J. Neurosci. 4: 1944-1953.

Black, M., J. M. Aletta, and L. Greene (1986) Regulation of microtubule composition and stability during nerve growth factor-promoted neurite outgrowth. J. Cell Biol. 103: 545-557.

Bottenstein, J. E., and G. Sato (1979) Growth of a rat neuroblastoma cell line in a serum-free supplemented medium. Proc. Natl. Acad. Sci. USA 76: 514-519.

Bremer, E. G., S. Hakomori, D. Bowen-Pope, E. Raines, and R. Ross (1984) Ganglioside modulation of cell growth, growth factor binding and receptor phosphorylation. J. Biol. Chem. 259: 6818-6825.

Bremer, E. G., J. Schelessinger, and S. Hakomori (1986) Gangliosidemediated modulation of cell growth. Specific effects of GM3 on tyrosine phosphorylation of the epidermal growth factor receptor. J. Biol. Chem. 261: 2434-2440.

Brugg, B., and A. Matus (1988) PC12 cells express juvenile microtubule-associated proteins during nerve growth factor-induced neurite outgrowth. J. Cell Biol. 107: 643-650.

Busciglio, J., A. Ferreira, O. Steward, and A. Caceres (1987) An immunocytochemical and biochemical study of the localization of the microtubule-associated protein Tau during post-lesion afferent reorganization in the central nervous system of adult rats. Brain Res. 419: 244-252.

Byrne, M. C., R. W. Ledeen, F. J. Roisen, G. Yorke, and J. R. Sclafani (1983) Ganglioside-induced neuritogenesis: Verification that gangliosides are the active agents, and comparisons of molecular species. J. Neurochem. 41: 1214-1222.

Caceres, A., and O. Steward (1983) Dendritic reorganization in the denervated dentate gyrus of the rat following entorhinal cortical lesions: A Golgi and electron microscopic study. J. Comp. Neurol. 214: 387-403.

Caceres, A., L. Binder, and G. Banker (1986) Immunocytochemical localization of tubulin and the microtubule-associated protein 2 during the development of hippocampal neurons in culture. J. Neurosci. 6: 714-722.

Caceres, A., J. Busciglio, A. Ferreira, and O. Steward (1988) An immunocytochemical and biochemical study of the microtubule-associated protein MAP-2 during post-lesion dendritic remodeling in the nervous system of adult rats. Mol. Brain Res. 3: 233-246.

Cambray-Deakin, M., A. Morgan, and R. D. Burgoyne (1987) Sequential appearance of cytoskeletal components during the early stages of neurite outgrowth from cerebellar cells in vitro. Dev. Brain Res. 37: $197-207$.

Couchie, D., A. Faivre-Bauman, J. Puymirat, J. Guilleminot, A. TixierVidal, and J. Nunez (1986) Expression of microtubule-associated proteins during early stages of neurite extension by brain neurons cultured in defined medium. J. Neurochem. 47: 125-1261.

Doherty, P., G. Dickson, T. P. Flanigan, and F. S. Walsh (1985) Ganglioside GMl does not initiate, but enhances neurite regeneration of nerve growth factor-dependent sensory neurons. J. Neurochem. 44 1259-1265.
Dotti, C. G., C. Sullivan, and G. Banker (1988) The establishment of polarity by hippocampal neurons in culture. J. Neurosci. 8: 14541468.

Drubin, D., S. C. Feinstein, E. M. Shooter, and M. W. Kirschner (1985) Nerve growth factor induced neurite outgrowth in $\mathrm{PCl} 2$ cells involves the coordinate induction of microtubule assembly and assembly promoting factors J. Cell Biol. 101: 1790-1807.

Drubin, D., S. Kobayashi, D. Kellog, and M. W. Kirschner (1988) Regulation of microtubule protein levels during cellular morphogenesis in nerve growth factor-treated PC1 2 cells. J. Cell Biol. 106: $1583-$ 1591.

Facci, L., A. Leon, G. Toffano, S. Sonnino, R. Ghidoni, and G. Tettamanti (1984) Promotion of neuritogenesis in mouse neuroblastoma cells by exogenous gangliosides. Relationship betwecn the cffect and the cell association of ganglioside GM1. J. Neurochem. 42:299305.

Ferrari, G., M. Fabris, and G. Gorio (1983) Gangliosides enhance neurite outgrowth in PC12 cells. Dev. Brain Res. 8: 215-222.

Ferreira, A., and A. Caceres (1989) The expression of acetylated microtubules during axonal and dendritic growth in cerebellar macroneurons which develp in vitro. Dev. Brain Res. 49: 205-213.

Ferreira, A., J. Busciglio, and A. Caceres (1987) An immunocytochemical and biochemical analysis of the ontogeny of the microtubule associated proteins MAP-2 and Tau in the nervous system of the rat. Dev. Brain Res. 34: 9-31.

Ferreira, A., J. Busciglio, and A. Caceres (1989) Microtubule formation and neurite growth in cerebellar macroneurons which develop in vitro: Evidence for the involvement of the microtubule-associated proteins, MAP-1a, HMW-MAP2 and Tau. Dev. Brain Res. 49: 215228.

Fisher, I., T. Shea, V. Sapirstein, and K. Kosik (1986) Expression and distribution of microtubule-associated protein 2 (MAP-2) in neuroblastoma and primary neuronal cells. Dev. Brain Res. 25: 99-109.

Gorio, A., L. Carmignoto, L. Facci, and M. Finesso (1980) Motor nerve sprouting induced by ganglioside treatment. Possible implications for gangliosides on neuronal growth. Brain Res. 197: 236-241.

Gorio, A., P. Marini, and R. Zanoni (1983) Muscle reinervation. III. Motoneuron sprouting capacity, enhancement by exogenous gangliosides. Neuroscience $8: 417-429$.

Gravotta, D., C. A. Landa, P. Panzetta, and H. Maccioni (1989) In vivo and in vitro expression of gangliosides in chick retina Muller cells. J. Neurochem. (in press).

Greene, L. A., R. K. H. Liem, and M. Shelanski (1983) Regulation of a high molecular weight microtubule-associated protein in PC 12 cells by nerve growth factor. J. Cell Biol. 96: 76-83.

Hoffman, P. N., and R. J. Lasek (1980) Axonal transport of the cytoskeleton in regenerating motor neurons; constancy and change. Brain Res. 202: 317-333.

Hollmann, M., and W. Seifert (1986) Ganglioside modulate glutamate receptor binding in rat brain synaptic membranes. Neurosci. Lett. 65 : 133-138.

Jacobs, J. R., and J. K. Stevens (1986) Changes in the organization of the neuritic cytoskeleton during nerve growth factor-activated differentiation of PC 12 cells: A serial electron microscopic study of the development and control of neuritic shape. J. Cell Biol. 103: 895906.

Katoh-Semba, R., S. D. Skaper, and S. Varon (1984) Interaction of GM1 ganglioside with PC12 pheochromocytoma cells: Serum and NGF-dependent effects on neuritic growth (and proliferation). J. Neurosci. Res. 12: 299-310.

Koulakoff, A., B. Bizzini, and Y. Berwald-Netter (1983) Neuronal acquisition of tetanus toxin binding sites: Relationship with the last mitotic cycle. Dev. Biol. 100: 350-357.

Laemmli, U. K. (1970) Cleavage of structural proteins during the assembly of the head of bacteriophage $T 4$. Nature 227: 680-685.

Lasek, R. J. (1981) The dynamic odering of neuronal cytoskeleton. Neurosci. Res. Prog. Bull. 19: 7-31.

Leon, A., R. Del Toso, D. Presti, D. Benvegnu, L. Facci, G. Kirschner, G. Tettamanti, and G. Toffano (1988) Development and survival of neurons in dissociated fetal mesencephalic serum-free cell cultures: II. Modulatory effects of gangliosides. J. Neurosci. 8: 746-753.

Maccioni, H., P. Panzetta, and C. Landa (1988) Biosynthesis and expression of gangliosides during neural differentiation. In New Trends in Ganglioside Research: Neurochemical and Neuroregenerative Aspects. Fidia Res. Ser. 14: 295-305. 
Matta, S. G., G. Yorke, and F. J. Roisen (1986) Neuritogenic and metabolic effects of individual gangliosides and their interactions with nerve growth factor in cultures of neuroblastoma and pheochromocytoma. Dev. Brain Res. 27: 243-252.

Matus, A. (1988) Microtubule-associated proteins: Their potential role in determining neuronal morphology. Annu. Rev. Neurosci. 11:2943.

Matus, A., R. Bernhardt, R. Bodner, and D. Alaimo-Beuret (1986) Microtubule-associated protein 2 and tubulin are differently distributed in the dendrites of developing neurons. Neuroscience 17: 371389.

Mitchison, T., and M. W. Kirschner (1988) Cytoskeletal dynamics and nerve growth. Neuron 1: 761-772.

Robb, G. A., and J. Keynes (1984) Stimulation of nodal and terminal sprouting of mouse motor neurons by gangliosides. Brain Res. 295: 368-371.

Ryback, S., I. Ginzburk, and E. Yavin (1983) Gangliosides stimulate neurite outgrowth and induce tubulin mRNA accumulation in neural cells. Biochem. Biophys. Res. Commun. 116: 974-980.

Sbasching-Agler, M., R. W. Ledeen, B. Grafstein, and R. M. Alpert (1984) Ganglioside changes in the regenerating gold fish optic system: Comparisons with glycoproteins and phospholipids. J. Neurosci. Res. 12: 221-232.

Skaper, S. D., L. Katoh-Semba, and S. Varon (1985) GM1 ganglioside acrelerates neurite outgrowth from primary peripheral and central neurons under selective culture conditions. Dev. Brain Res. 23: 1926

Sparrow, J. R., and B. Grafstein (1982) Sciatic nerve regeneration in ganglioside-treated rats. Exp. Neurol. 77: 230-235.

Spero, D., and F. Roisen (1984) Ganglioside-mediated enhancement of the cytoskeletal organization and activity in neuro-2a neuroblastoma cells. Dev. Brain Res. 13: 37-48.

Spiegel, S., P. H. Fishman, and R. J. Weber (1985) Direct evidence that endogenous GM1 ganglioside can mediate thymocite proliferation. Science 230: 1285-1287.

Spoerri, P. E., M. M. Rapport, S. P. Mahadik, and F. J. Roisen (1988) Inhibition of conditioned media-mediated neuritogenesis of sensory ganglia by monoclonal antibodies to GM1 ganglioside. Dev. Brain Res. 41:71-77.

Tettamanti, G. S., S. Sonnino, R. Ghidoni, M. Masserini, and B. Venerando (1985) Chemical and functional properties of gangliosides. Their possible implications in the membrane mediated transfer of information. In Physics of Amphiphiles: Micelles, Vesicles and $\mathrm{Mi}$ croemulsions, V. de Giorgio and M. Corti, eds., pp. 607-636, XC Corso Soc. Italiana di Fisica, Bologna.

Willinger, M., and M. Schachner (1980) GM1 ganglioside as a marker for neuronal differentiation in mouse cerebellum. Dev. Biol. 74: 101117 